\title{
Licenciatura em Educação Física: Concepções a partir da Vivência Experienciada dos Professores do Ensino Superior em seu Percurso Formativo ${ }^{1}$
}

\author{
Leonardo Germano Krüger* \\ Hugo Norberto Krug***
}

\begin{abstract}
Resumo: Este artigo visa divulgar a compreensão das concepções da formação de professores da Licenciatura em Educação Física a partir da narrativa dos professores envolvidos no processo de construção e implantação do projeto políticopedagógico e reestruturação curricular do ano de 2004, do CEFD/UFSM. Apresentamos, então, o entendimento de que as aprendizagens mostram-se como a percepção da atuação de si próprio durante as vivências, assumindo um caráter formativo das suas concepções.
\end{abstract}

Palavras-chave: Educação Física. Narrativa. Educação Superior.

\section{PROPÓSITO DA INVESTIGAÇÃO}

Falar, escrever e pesquisar sobre formação de professores nos remete a constatar que esse campo vem desenvolvendo-se sob constantes transformações, ora através da reestruturação legislativa, ora sob novas formas de propostas curriculares e parâmetros que sugerem mudanças em todos os níveis de ensino.

\footnotetext{
'Artigo embasado na Dissertação intitulada: "As concepções da formação profissional da Licenciatura em Educação Física: trajetórias docentes e suas perspectivas contributivas", apresentada à linha de pesquisa Formação, Saberes e Desenvolvimento Profissional, do curso de Mestrado em Educação (PPGE/CE/UFSM).

* Mestre em Educação (UFSM). Professor Substituto do Departamento de Metodologia do Ensino; atua no curso de Licenciatura em Educação Física (UFSM). Integrante do Grupo de Estudos e Pesquisas em Educação Física (GEPEF), vinculado ao Centro de Educação da Universidade Federal de Santa Maria. Santa Maria, RS, Brasil. E-mail: leonardogk@gmail.com ** Doutor em Educação e em Ciência do Movimento Humano (UFSM). Professor do Departamento de Metodologia do Ensino; atua nos cursos de Licenciatura em Educação Física, Especialização em Educação Física Escolar e Mestrado em Educação (UFSM). Integrante do Grupo de Estudos e Pesquisas em Educação Física (GEPEF), vinculado ao Centro de Educação da Universidade Federal de Santa Maria - Santa Maria, RS, Brasil. E-mail: hnkrug@bol.com.br
} 
Nesse âmbito de transformações visíveis, porém às vezes imperceptível, aprender a ser professor e ser formador de professor associam-se às tentativas de mudanças na medida em que estas acompanham o sujeito em seu desenvolvimento profissional, isto é, na compreensão da constituição do "professor-como-profissional a professor-como-pessoa" (GOODSON, 1992, p. 73). Esse entrelaçamento torna-se um desafio para percebermos o mundo a nossa volta, nas escolhas e na direção que damos a nossa vida e a própria profissão a partir das vivências experienciadas do contexto formativo pessoal e profissional.

O desenvolvimento do conhecimento, de formas de aprender e construir conhecimento, aliado à capacidade de relacionar o dinamismo das transformações que ocorrem no mundo da economia globalizada e no mundo do trabalho, estendendo-se à reflexão e discussão de quadros teóricos que cada profissional constrói no seu percurso do desenvolvimento profissional à percepção de sentimentos e emoções, a valoração de concepções e crenças, gradativamente, constituem-se nas intenções e dimensões no desenvolvimento de cada pessoa, no aspecto intra e interpessoal, acompanhando-a em um processo complexo e multimediado.

O convívio entre gerações, pais e filhos, amigos e amigas, professores e alunos, ensino superior e mercado de trabalho, por exemplo, trazem em si as relações e tensões que podem caracterizar a mediação e constituição profissional. Neste sentido, em um estudo que realizamos com os graduandos do primeiro semestre do ano de 2005 do curso de Licenciatura Plena em Educação Física, do Centro de Educação Física e Desportos da Universidade Federal de Santa Maria (CEFD/UFSM), foi possível constatar, através das suas trajetórias vivenciadas no seu tempo e espaço da formação inicial, a formação e concepções de ser professor e de como eles se percebem na futura profissão, bem como percebemos a extrema desvalorização do contexto escolar durante a formação inicial (KRÜGER; KRUG, 2006).

Motivado a partir deste estudo, tivemos a oportunidade para direcionar a presente investigação para a formação do professor universitário, a sua trajetória docente, seus desafios e possibilidades de atuação no espaço universitário. Assim, a partir do estudo das

Movimento, Porto Alegre, v. 15, n. 01, p. 51-70, janeiro/março de 2009. 
vivências experienciadas no percurso formativo de professores universitários, objetivamos compreender as concepções da formação de professores da nova Licenciatura em Educação Física do CEFD/ UFSM, envolvidos no processo de construção e implantação do projeto político-pedagógico e reestruturação curricular do ano de 2004.

Esta preocupação advém do entendimento de que a Educação Física Escolar, do modo produtivo como ainda é oferecida - rotulada como uma disciplina essencialmente prática, que não trabalha valores para além da aptidão física, da esportivização técnica e mecanicista -, não tem mais espaço no contexto educacional de hoje. Além disso, em função do profissional de Educação Física ainda não gozar um sentimento de legitimação social e autonomia acadêmica que enseje autoconfiança pessoal e profissional, os cursos de formação continuam apontando mais a manutenção de uma tradição instrumentalizadora do que as rupturas formativo-culturais idealizadas, conforme comenta Andrade Filho (2001).

Além disso, as reformas educacionais - no tocante a formação de professores no contexto do ensino superior - vivenciam momentos de avanços, se comparada com outros momentos históricos e em relação a outros países, como podemos evidenciar na obra de Marcelo García (1999), ligeiramente atrasada ou ultrapassada.

Em se tratando do modo produtivo do sistema educacional brasileiro, Frigotto (2001) comenta que as preocupações das reformas objetivam adequar o sistema de ensino ao processo de reestruturação produtiva aos rumos do Estado e, por isso, estão estrategicamente no centro das suas preocupações dos embates políticos atuais.

Neste contexto, o professor universitário aparece como o agente produtor de saberes, responsável pelo reencaminhamento no que diz respeito à formação de gerações, à construção da identidade e profissionalização docente do futuro professor da Educação Básica. Refletir sobre essa responsabilidade conduz a fazer escolhas e posicionar-se em defesa da formação de recursos humanos com vista a construir um projeto educacional em uma sociedade que consente ou que caminhe para ser diferente da que temos hoje. Tarefa árdua e nada fácil.

Movimento, Porto Alegre, v. 15, n. 01, p. 51-70, janeiro/março de 2009. 
Diante destas tarefas, Pimenta; Anastasiou; Cavallet (2002) ressaltam que repensar a instituição universidade e a docência tornase uma necessidade premente, refletindo, principalmente, no que se fez na intencionalidade de avançar no próprio desenvolvimento profissional e institucional por meio da preparação político-pedagógica.

Ademais, compreender tais tarefas e de como elas se concretizam na prática educacional exige estudarmos as experiências vivenciadas no percurso formativo dos professores, o que poderá apontar para as diversas alternativas na profissão e para o "modelo" de professor e pesquisador universitário, sobre o que sustenta e alimenta as suas práticas educativas, bem como compreender como se produzem a vida, a profissão e a instituição. Assim, discutir a formação do professor universitário e suas contribuições para o profissional a ser formado remete-nos, como menciona Batista; Batista (2002), às opções realizadas no interior das relações sociais, no compromisso profissional com a docência e na assunção de uma postura éticopolítica diante das ações acadêmicas.

Neste sentido, pretendemos contribuir para a instituição universitária e seus professores, ampliando e dinamizando a qualificação de todos os envolvidos no processo de construção e edificação da concepção de formação e formação de professores do CEFD/UFSM. De forma mais ampla, esperamos que os achados desta investigação possam somar com a discussão que vem sendo gradativamente desenvolvida no tocante da formação de professores e seu desenvolvimento profissional. Para tanto, o propósito dessa investigação exigiu-nos a narrativa oral como instrumento metodológico.

\section{CAMINHO PERCORRIDO: AS NARRATIVAS DOS PROFESSORES- PERSONAGENS}

As atividades que compunham a proposta metodológica desta investigação vinculam-se as nossas ações enquanto um "aprendenteinvestigador”. Essa expressão utilizada por Josso (2002) nos faz pensar no tempo que passou, dos caminhos percorridos que perduram nas constantes indagações objetivadoras e subjetivadoras a procura

Movimento, Porto Alegre, v. 15, n. 01, p. 51-70, janeiro/março de 2009. 
de uma justificativa para o sentido do nosso percurso formativo. Dessa forma, as vivências experienciadas ganham vida nos múltiplos desejos e intenções de uma mediação com a construção do conhecimento, com o intuito de perceber as suas contribuições naquilo que vivemos e fazemos no dia-a-dia, pois como menciona Wittizorecki et al. (2006), pesquisar exige interrogar-se.

A partir disso, a nossa investigação teve como referencial a pesquisa qualitativa em que a compreensão de uma realidade social está sujeita as diferentes reinterpretações, pois estamos nos inserindo em um contexto em constante transformação. Estamos percorrendo um caminho que busca compreender posicionamentos, conflitos e interesses, presente na estrutura da realidade (TRIVIÑOS, 1987).

A fim de argumentar as nossas ações, fundamentamos este estudo em dois campos teóricos metodológicos: um, a caracterização como estudo de caso com base nas idéias de André (2005) e Molina (1999); dois, referimo-nos ao campo da trajetória docente dos professores do ensino superior com ênfase na narrativa das suas vivências experienciada no percurso pessoal e profissional. Para esse entendimento, buscamos referência nos estudos de Oliveira (2006), Bolívar (2002) e Josso (2002).

A escolha do estudo de caso envolveu uma instância em ação, ou seja, o caso escolhido para ser estudado guarda estreita relação com o objetivo desta investigação e, ao elegermos a narrativa oral como principal instrumento para obter as informações, permitiu-nos proporcionar relevância às vivências e as representações individuais na constituição do percurso formativo, rememoradas e registradas a partir dos encontros com os professores-personagem, isto é, da relação entre o narrador e o pesquisador.

A denominação professores-personagem deve-se ao fato de que os professores são personagens, sujeitos históricos que participam como atores na construção de uma realidade social. Neste sentido, tendo como base a Resolução CNE/CP N 01 e 02/2002 (BRASIL, 2002a;b), o CEFD se organizou a partir de uma Comissão a fim de ancorar as discussões sobre a estruturação e implantação do projeto político-pedagógico e reestruturação curricular (CEIPPP/RC). Assim,

Movimento, Porto Alegre, v. 15, n. 01, p. 51-70, janeiro/março de 2009. 
os quatro professores representantes desta Comissão foram os personagens da investigação.

Após o convite e a explanação do objetivo da investigação, eles participaram narrando as suas vivências experienciada no percurso formativo, bem como temas relacionado as suas práticas em um processo conjunto, pessoal, profissional e contextual, entrelaçandoos a CEIPPP/RC. Então, foi proporcionado ao informante seguir a linha de raciocínio das suas experiências dentro do foco principal colocado pelo investigador. Isso implica segundo Bolívar (2002), no caráter biográfico de como os professores se mostram quando falam de si, da profissão e do contexto, o que vai permitir assentar a formação nas suas vivências do ciclo vital.

Josso (2002, p. 91) explica que ao colocarmos o professor em contato consigo próprio, lhe é exigido uma prática reflexiva com esse "si próprio", que tomou e continua a tomar formas múltiplas e que se transforma através dela, "que permite a cada um encontrar (...) nos seus pensamentos, nas suas actividades por meio de uma atenção consciente ao que é utilizado de si nos lugares em que se está e nas actividades que aí realizam".

Ademais, as gravações das narrativas dos professores-personagem foram transcritas, lidas e aprovadas pelos autores, para em seguida, iniciar sua análise. Além das narrativas, também tivemos a oportunidade de visitar alguns documentos, dentre eles: o Projeto Político-Pedagógico (PPP) da UFSM, o Projeto Político-Pedagógico do novo curso Licenciatura em Educação Física e as Atas dos encontros da CEIPPP/RC, que serviram como fonte de dados factuais do contexto investigado.

Seguimos as orientações de Jovchelovitch; Bauer (2003) para a análise interpretativa, a qual partiu da transcrição das narrativas a uma redução gradativa do texto. Este procedimento se caracterizou pelas seguintes fases: a) Iniciamos com a transcrição das narrativas visando ter a apreensão do material, considerando, mesmo que superficialmente, a primeira análise e o fluxo das primeiras idéias para interpretar o texto; b) A partir de então, procuramos sintetizar passagens inteiras ou parágrafos narrados pelos professores-personagem

Movimento, Porto Alegre, v. 15, n. 01, p. 51-70, janeiro/março de 2009. 
visando à identificação de um foco temático. Este processo foi realizado para cada narrativa até o momento em que atingiram o foco temático; c) Posteriormente, foi ordenado em um sistema de entrelaçamento de significado temático para todas elas, para em seguida, atingirmos palavras-chave retratando a formação de unidades de significado para todas as narrativas e; d) Por último, ainda realizamos uma revisão para nos reiterar da constituição dos achados da investigação.

Ademais, a aproximação entre a análise temática das narrativas e a análise documental contribuiu para identificar momentos comuns, críticos e/ou conflituosos, auxiliando na constituição das unidades de significado formuladas a partir do contexto investigativo.

Assim, a partir da narrativa dos professores-personagem procuramos relacionar a sua história contada com estudos da literatura a fim de comunicar os achados da investigação de forma satisfatória, capaz de fornecer condições alternativas e pistas para estudos futuros à luz das interpretações. Esperamos ter provocado o mínimo de movimento aos professores-personagem ao exigir momentos reflexivos, articulando as suas concepções teóricas, o contexto social do CEFD e as vivências experienciadas no percurso formativo, os seus medos, dificuldades, incertezas e desafios.

\section{UM MUNDO QUE SE MOSTRA}

Focalizando o objetivo da nossa investigação, as unidades de significado que emergiram a partir das vivências experienciadas dos professores-personagem foram construídas ao irmos ziguezagueando por entre as narrativas e os documentos mencionados anteriormente, a saber:

a) projeto educativo: informação e conhecimento em a-tuaação - Na construção do PPP, essa unidade de significado se apresentou como um movimento que envolveu a prática e autores diversos em um procedimento flexível, construído no dia-a-dia pela CEIPPP/ RC. Nesse procedimento permeou concepções que estão sendo um desafio para reaprender às intenções do próprio PPP, o que está

Movimento, Porto Alegre, v. 15, n. 01, p. 51-70, janeiro/março de 2009. 
intimamente relacionado à capacidade de observar e perceber o contexto social a partir da participação de um grupo ou de um coletivo em função da idéia de complexidade.

Esta concepção preconiza a superação do modelo técnico e da racionalização do ensino. Com isso, busca-se a descentralização da transmissão de conteúdos e/ou uma verdade científica em prol da construção do saber a partir da contextualização da realidade social. Neste sentido, as narrativas deixam implícita a razão particular de cada professor ao se posicionar contra ou a favor de algumas mudanças, tal como a proposta dos Jogos Esportivos Coletivos, fazendo reaparecer o sujeito face às estruturas que de alguma forma, conseguem a valorização das suas ações, sendo estas contrárias ou não. Somos diretos, então, ao deixar em aberto as seguintes questões em face do projeto educativo do PPP: o vivido face ao instituído? A valorização do sujeito e a sua vivência ou a reprodução da vivência de outrora? Quais as necessidades formativas dos professores que favoreçam a implantação do projeto? Que atividades formativas podem expressar maior capacidade para a reflexão dos professores? Como os professores planejam as disciplinas e desenvolvem os conteúdos para se transformarem em proposta de ensino que correspondam às condições de atividades formativas do PPP? Que estratégias essas atividades contêm?

Ademais, também percebemos que as concepções práticas que permeiam o projeto educativo procuram integrar as temáticas similares que constituem as diferentes disciplinas da grade curricular buscando a aproximação com a Educação Física Escolar ao longo do curso. Entendemos que esta concepção difere-se daquelas que fizeram parte da formação dos professores-personagens, assim como a situação que segue.

A aproximação da escola com a formação inicial da Licenciatura em Educação Física presente nas narrativas dos professores possibilitam enfatizar a necessidade da coletividade no trabalho docente, confirmada por Nóvoa (1992a) como um momento compartilhado capaz de produzir a profissionalização docente.

Baseando-nos nesta idéia, é na coletividade que podemos perceber o interesse político durante a discussão da construção da grade

Movimento, Porto Alegre, v. 15, n. 01, p. 51-70, janeiro/março de 2009. 
curricular, bem como de algumas disciplinas. Acreditamos que esses momentos trouxeram à tona a história de vida dos professores, apresentando crenças, ideologias e valores, bem como essas diferentes características proporcionaram enriquecimento para a discussão, gerando importantes reflexões frente à proposta do PPP. Por outro lado, elas também se apresentaram como um fator de resistência, talvez em exigir que alguns professores transcendam a sua comodidade e passividade com o compromisso de assumir o projeto educativo.

No entendimento da análise das narrativas, as reais condições de efetivação das mudanças a partir do PPP não são imediatas, mas abrangentes, revelados através da consciência e autonomia dos professores firmados com o projeto institucional. A partir da compreensão deste projeto como diagnóstico da realidade, o mesmo pode se constituir parte do processo formativo do professor, além de objetivá-lo com primazia nas questões centrais a serem desenvolvidas (PIMENTA; ANASTASIOU, 2002).

b) Aprendizagem inter-relacional - Essa unidade de significado também se apresentou como uma habilidade de reconhecimento compartilhada na relação dos professores com a organização institucional, entre os próprios professores e com os alunos, em que há a possibilidade de todos se tornarem aprendentes em um contexto formativo. Nessa perspectiva, professores e alunos podem aprender significativamente ao compreender temáticas, ressignificando conceitos e conhecimentos a partir da reflexividade, assim como construir aportes teóricos à compreensão da cultura corporal, historicamente produzida pelo homem. De certa forma, essa necessidade torna-se um desafio porque rompe com o olhar naturalista sobre o qual muitas vezes a cultura do movimento é observada, explicada, classificada e tratada.

Nada disso, contudo, representa ser exclusivo de uma pessoa neste novo momento. Freire (2000) argumenta que os professores podem trazer na sua coerência profissional a sensibilidade à leitura individual e à releitura grupal, o que não se faz sem humildade e abertura ao risco à aventura do espírito, radicando aí, a educabilidade, bem como a nossa inserção em um permanente movimento de busca

Movimento, Porto Alegre, v. 15, n. 01, p. 51-70, janeiro/março de 2009. 
em que não apenas nos damos conta das coisas, mas também delas podemos ter um conhecimento cabal, isto é, rigoroso e categórico.

Neste sentido, Josso (2002) destaca que estas construções experienciais vão constituindo os valores de vida, e assim, ressignificando os próprios referenciais teóricos. Estes por sua vez, são marcas que diferenciam o sentido atribuído por cada participante ao seu projeto de estudos no cenário universitário. Dessa forma, a projeção de si em projetos em médio prazo, por exemplo, poderá fazer com que os pares certifiquem-se do delineamento necessário daquilo em que desejam tornar-se, num fazer e num ser, em relação aos projetos institucionais.

Esta concepção também indica um debruçar-se intenso do professor em ter uma orientação que transcenda a compreensão de um simples especialista que conheça bem um único tipo de conhecimento e sabe explicá-lo. Esse exemplo explicita o percurso formativo do professor universitário, pois dependendo da sua objetividade e/ou subjetividade vivida, o envia para a definição de si para rotulagens feita pelos outros, sendo, portanto, como afirma Dubar (1997a, p. 235), formas identitárias.

Estas formas identitárias podem ser interpretadas
a partir dos modos de articulação entre transacção
objectiva e transacção subjectiva, como resultados
de compromissos "interiores" entre identidade her-
dada e identidade visada, mas também de negocia-
ções "exteriores" entre identidade atribuída por outro
e identidade incorporada por si.

Isto também implica dizer que as formas identitárias estão entrelaçadas ao processo da profissionalização docente, que, no entender de Nóvoa (1992a), é um processo através do qual os professores elevam o seu rendimento e aumentam o seu poder de autonomia. Neste sentido, poderão apoiar-se cada vez mais nas suas vivências experienciadas e capacidades adquiridas ao longo do seu percurso formativo.

Em suma, os professores apresentaram as suas concepções de aprendizagem como um jogo social em que os participantes são fundamentais. A co-participação, por ora no papel do aluno ou do

Movimento, Porto Alegre, v. 15, n. 01, p. 51-70, janeiro/março de 2009. 
professor, conferem imagens e interpretações para os fatos que estão acontecendo naquele instante, logo, o espaço coletivo criado se responsabiliza por mediar e oferecer subsídios para perceber até que ponto as intenções políticas estão sendo incorporadas na própria prática, o que poderá enriquecer o conhecimento advindo da própria formação, ou seja, ressignificando o conhecimento construído na inter-relação pessoal e profissional no ciclo vital.

c) Uma coisa no ar... um olhar para nós - Expôs a consciência profissional que os professores-personagem construíram na relação teoria e prática e, hoje, refletem na sua postura que imprimem aos fatos e ao mundo. Sendo assim, também se mostram na capacidade de auto-avaliar e perceber que é necessário um mínimo de coerência no e com o projeto educativo, assumindo-o como um compromisso viável à formação de futuros professores.

Neste sentido, a participação dos professores-personagem no cenário institucional universitário precisa constituir-se em uma rede de significados entre os próprios professores e o meio social, em que se discutem e ajustam as relações, os interesses e os conflitos. Assim, nos constrangimentos ou na conquista, percebemos que a cultura docente não se dá de maneira isolada nem como decorrente de fatos sem sentido. Porém, podemos vê-la como um processo histórico que, na realidade atual do CEFD, ainda exerce alguns condicionantes de outrora.

Obviamente, há heranças históricas e culturais no contexto do CEFD, porém, como diz Nóvoa (1992b), não podemos reduzir algumas delas a poucas variáveis para manipular. Trabalhar com e sobre tais vivências provavelmente gerará uma proposta avaliativa e formativa que atinja profundamente o conjunto de significados, crenças e valores dos professores, incorporando necessariamente "um conceito ecológico de mudança" em que "os indivíduos mudam, mudando o próprio contexto em que trabalham" (CANÁRIO apud BARROSO, 1997, p. 74).

Neste sentido, parece estar presente um momento de desconstrução a partir de repensar a própria prática docente como uma estratégia de ruptura, autonomia e emancipação, ou fortalecimento das

Movimento, Porto Alegre, v. 15, n. 01, p. 51-70, janeiro/março de 2009. 
concepções já enraizadas tendo em vista o projeto educativo formador, nas quais, muitas vezes, o professor é visto como um modelo formativo para o aluno.

O esforço na busca da desconstrução poderá trazer saídas possíveis e avanços significativos para a formação e atuação docente. Esta forma de desenvolvimento profissional comporta um desafio identitário (DUBAR, 1997b). Na opinião do autor, querer fazer passar os professores de uma forma identitária para uma outra constitui um objetivo muito ambicioso que lhe exige, ao mesmo tempo, que mude a configuração dos saberes e a relação vivida com e no trabalho.

Para tanto, podemos refletir para o que Pimenta; Anastasiou (2002) chamam de desenvolvimento da profissionalização continuada. Através das narrativas dos professores-personagem, parece-nos que algumas necessidades já foram detectadas. Em função do que propõem as autoras, o próximo passo é sistematizar a partir do foco do projeto educativo, sob o ponto de vista organizacional e pedagógico, ações coletivas objetivando colocar os professores em condições de reelaborar seus saberes, inicialmente considerados como verdades, em confronto com as práticas quotidianas.

Esta constatação é traduzida em desafios e dificuldades. Dificuldades em dar objetividade na ação docente, em reencontrar-se novamente consigo mesmo e projetar-se ao desafio com o projeto educativo. Assim, aproveitamos esse espaço para delinear duas questões.

A primeira focaliza a necessidade dos professores continuarem a tomar consciência de seus processos formativos, refletindo sobre si próprio e, ao mesmo tempo, estarem cientes de que este é um dos caminhos para a aprendizagem docente em um contexto de mudança. A segunda trata da tessitura de uma rede de interações para a construção do conhecimento em prol do projeto educativo formador, possibilitando, não só através do diálogo, mas também a partir de dinâmicas que viabilizem momentos para compartilhar ações e reflexão sobre idéias, opiniões e contradições, que poderão emergir da mediação de um processo interativo interdependente, capaz de permitir a construção dos novos rumos da formação inicial e do próprio desenvolvimento profissional. Parafraseando Morin (2003), perceber o contexto

Movimento, Porto Alegre, v. 15, n. 01, p. 51-70, janeiro/março de 2009. 
educacional em uma visão global a fim de despertar desejos e paixões humanas que ultrapassem os meros interesses da instrução técnica.

\section{AS RESSIGNIFICAÇÕES DOCENTES}

A reflexão que buscamos realizar a partir do objetivo proposto para esta investigação indicou elementos essenciais para a compreensão do processo de implantação do novo currículo da Licenciatura em Educação Física. Estamos nos referindo ao projeto formador do CEFD, ou seja, a construção do seu primeiro PPP.

Ao levarmos em consideração o contexto deste Centro, percebemos que o processo histórico exerceu influências na construção do PPP, pois através da retrospectiva de alguns estudos realizados no Programa Pós-Graduação em Ciência do Movimento Humano PPGCMH/CEFD/UFSM - (MUNARO, 1984; MAZO, 1991; BAGGIO, 2000; KRÜGER; KRUG, 2006; SANTOS Jr., 2006; MICHELOTTI; SOUZA, 2006), eles "sempre" estavam apontando a construção de um projeto emancipador contextualizado com a realidade escolar.

Isto deixa implícito que as concepções dos professores foram sendo reconstruídas ao longo da sua inserção no contexto universitário e que, agora, estão ganhando vez e voz no eco das necessidades formativas. Neste sentido, as unidades de significado apresentadas apontaram como os professores-personagem se perceberam ao contar as vivências experienciadas na sua formação, bem como o seu envolvimento na CEIPPP/RC. Esse resgate foi importante para observarmos os distintos momentos do seu desenvolvimento profissional, assim como de pessoas e as situações no convívio coletivo, por exemplo - por ora não mencionados no texto, que os influenciaram na edificação das suas concepções. Assim, os professores foram considerados como personagem da nossa investigação porque foram sujeitos da própria história que contaram, deixando de ser objeto de estudo.

Sintetizando a compreensão das unidades de significado, elas indicam estreita relação com o PPP (CEFD, 2005), caracterizando-se em uma visão holística e ecológica, expressando, assim, a conscientização

Movimento, Porto Alegre, v. 15, n. 01, p. 51-70, janeiro/março de 2009. 
em assumir a construção de um projeto educativo entrelaçado com o entendimento de que o processo inter-relacional é capaz de produzir mudanças a partir de novas aprendizagens, as quais foram percebidas como reflexo da atuação de si próprio durante o processo de construção do PPP e da reestruturação curricular.

Com isto, deixa-se de perceber as circunstâncias como ocasionais, mas em que se busca discutir as exigências educacionais, como por exemplo, a contextualização do conteúdo e da própria prática do professor no sentido da superação da individualidade. Esta proposição faz com o desenvolvimento do PPP não se restrinja ao aluno, mas que também se volte para estratégias formativas para a conduta do professor. Assim, o próprio PPP ilustra esta urgência: com isso fica evidente que as propostas de Morin (2002) de estudar a questão do conhecer o conhecer ou, no dizer de Maturana (1995), do observar o observar do observador, devem ser urgentemente levadas a sério pelos cursos acadêmicos (CEFD, 2005).

Deste modo, talvez, poderemos estar nos encaminhando para "cuidar de nosso coletivo" no sentido de buscar aproximar professores não apenas de uma linha de pensamento e/ou pesquisa. Por isso, registramos alguns indícios do que é possível a partir das narrativas dos professores e do próprio PPP:

Por exemplo, esse grupo que está pensando os jogos esportivos coletivos nós estamos nos encontrando. Vendo como a gente vai fazer, avaliando o primeiro semestre, vendo como é que vem o aluno do outro semestre, vendo como é que vai ser a participação do outro professor, a questão do conteúdo... Eu acho que a gente tem mais chance de acertar, e a nossa compreensão de que a gente vai ter que mudar a nossa prática sim. Agora, também, tem aquele professor que entende que o conhecimento dele é aquilo ali e que não é preciso mudar prática nenhuma pra traduzir essa formação do licenciado. E provavelmente são aqueles professores que estiveram longe dessa discussão [...] e acreditam que bastando fazer aquela informação, eles estão contribuindo; e de uma certa forma estão, mas descontextualizada, acrítica, não há uma interação. Nisso nós não avançamos. Isso é um retrocesso, é uma limitação, é um

Movimento, Porto Alegre, v. 15, n. 01, p. 51-70, janeiro/março de 2009. 


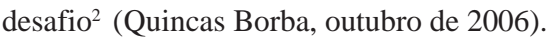

Os ajustes, eles são possíveis desde a implantação. Porque por isso que se chama Projeto. Projeto pode ser modificado sempre que você achar necessário. E penso que hoje nós já instauramos uma Comissão que está estudando reformas curriculares do Curso novo. Porque este é o processo ${ }^{4}$ (Brás Cubas, outubro de 2006).

A proposta do novo currículo requer discussões constantes entre toda comunidade acadêmica do CEFD e da UFSM, envolvida com o Curso de Educação Física; primeiro para implantar a grade curricular; segundo para avaliar a efetividade da proposta na prática; e terceiro para propor ajustes no projeto (CEFD, 2005).

Procurando contribuir com o exposto, Freire (2000) diz que não adianta o discurso competente se a ação pedagógica é impermeável a mudanças. Zabalza (2004) também afirma que a exigência de um projeto traz no seu bojo desafios e problemas. Neste sentido, ele diz que as instituições formadoras não podem limitar-se a dar respostas aos problemas, mas precisam procurar construir espaços para enfrentar tanto os ajustes necessários a serem incorporados como as novas expectativas e ideias. Consequentemente, as mesmas apresentam grande possibilidade de refletir sentimentos nos diversos setores envolvidos e, ao mesmo instante, auxiliar na aprendizagem institucional e a gerar por si mesma novas linhas de atuação.

Ademais, com base nas narrativas, reforçamos a necessidade de pensar a docência no ensino superior repensando sobre o próprio processo de formação. Provavelmente, ao reconstruir cada parte das experiências no percurso formativo, vai requer reflexão e auto-percepção sobre o pensar e agir do próprio professor no âmbito educativo. Nóvoa (1991) confirma esse posicionamento dizendo que podemos construir a formação através de um trabalho consciente de caráter reflexivo, apoiando a crítica sobre as próprias práticas e, assim, de reconstrução permanente da identidade profissional.

\footnotetext{
${ }^{2}$ Fragmento de uma das narrativas dos professores-personagem. O nome atribuído foi para preservar a identidade do Professor. Em função da proximidade com a leitura machadiana, optamos por fazer uma homenagem as suas obras através da denominação dos seus personagens.

Movimento, Porto Alegre, v. 15, n. 01, p. 51-70, janeiro/março de 2009.
} 
Pimenta; Anastasiou (2002) abordam um aspecto dessa questão ao dizer que os profissionais das várias áreas do conhecimento ministram aulas em decorrência de suas próprias atividades por diversas razões e interesses, mas poucas vezes eles se questionam sobre o que significa ser professor no ensino superior.

Neste sentido, a avaliação das atividades de desenvolvimento profissional precisa contemplar tanto o processo que envolve a implantação do PPP e as práticas dos professores quanto os resultados a que atinge. Ainda podemos selecionar outras variáveis a considerar, quais sejam os objetivos e estratégias. Por último, parece-nos necessário incorporar nas avaliações de atividades de formação de professores uma atenção especial para conhecer os efeitos que se produzem nos próprios professores, no seu envolvimento pedagógico com os alunos e com a instituição. Isso significa dizer que o processo precisa ser enfatizado trazendo aos professores uma série de elementos que fazem parte de todo um processo de formação, incluindo as suas dimensões pessoal e profissional.

Por conseguinte, os transtornos da formação em um curso de licenciatura também são entendidos como simples e complexos, além de requerer aprendizados éticos, pedagógicos, organizacionais e institucionais. Do ponto de vista simples porque lida com a vida quotidiana de quem ensina, aprende e pesquisa. Do ponto de vista complexo porque o quotidiano não é um espaço fechado, ligando-se a outros níveis da realidade, principalmente, ao buscar trabalhar as dimensões do PPP no seu sentido político-formativo, problematizando as relações da atuação docente na sala de aula, o próprio PPP e a realidade do contexto educacional da Educação Básica (VEIGA, 2006).

$\mathrm{Na}$ tentativa de concluir este espaço, parafraseamos a mesma autora ao apontar o PPP como um instrumento de oposição contra a homogeneidade, a fragmentação e a hierarquização que permeiam o quotidiano acadêmico. Enfim, a consciente (in)formação dos princípios norteadores do PPP atrelados ao processo de construção do conhecimento na realidade social, tendo como base a singularidade experiencial de cada sujeito na coletividade, pode constituir-se como espaço para reflexão e aprendizados, desde que aceitos no bojo de uma intenção emancipatória a partir da própria "a-tua-ação".

Movimento, Porto Alegre, v. 15, n. 01, p. 51-70, janeiro/março de 2009. 
Physical Education Graduate: conceptions from the experience of the teachers higher in its formative passage

Abstract: This article aims at to divulge the understanding of the teaching of conceptions of Physical Education Graduate from the narrative of the teachers higher involved in the construction process and implantation of the politician-pedagogical project and course reorganization of the year of 2004, of the CEFD/UFSM. We present, then, the agreement of that the learning reveal as the perception of the proper performance of itself during the experiences, assuming a formative character of its conceptions.

Keywords: Physical Education. Narration. Education.

Licenciatura en la Educación Física: conceptos de la práctica experienciada de los profesores de la educación superior en su paso formativo Resumen: Este artículo tiene como objetivo para divulgar la comprensión de los conceptos de la formación de los profesores del Licenciatura en la Educación Física de la narrativa de los profesores implicados en el proceso de la construcción y la implantación del proyecto político-pedagógico y de la reorganización del plan de estudios del año de 2004, del CEFD/UFSM. Presentamos el acuerdo de eso que los aprendizajes revelan como la opinión del funcionamiento apropiado de sí mismo durante las experiencias, si se asume que un carácter formativo de sus concepción.

Palabras-clave: Educación Física. Narración. Educación Superior.

\section{REFERÊNCIAS}

ANDRADE FILHO, N.F. de. Formação profissional em Educação Física brasileira: uma súmula da discussão dos anos de 1996 a 2000. Revista Brasileira de Ciências do Esporte. Campinas, v. 22, n. 3, p. 23-37, maio, 2001.

ANDRÉ, M.E.D.A. de. Estudo de caso em pesquisa e avaliação educacional. Brasília: Líber Livro, 2005.

BAGGIO, I. C. A prática curricular do CEFD/UFSM e o desenvolvimento das competências necessárias aos futuros professores de Educação Física

Movimento, Porto Alegre, v. 15, n. 01, p. 51-70, janeiro/março de 2009. 
para a promoção da autonomia em suas práticas pedagógicas. 2000. 194 fls. Dissertação (Mestrado em Educação Física) - Universidade Federal de Santa Maria. Santa Maria, 2000.

BARROSO, J. Formação, projecto e desenvolvimento organizacional. In: CANÁRIO, R. (Org.). Formação e situações de trabalho. Porto: Porto Ed., 1997, p. 6178.

BATISTA, S.H.S. da S.; BATISTA, N.A. A formação do professor universitário: desafios e possibilidades. In: SEVERINO, A.J.; FAZENDA, I.C.A. (Orgs.). Formação docente: rupturas e possibilidades. Campinas: Papirus, 2002, p. 185-205.

BOLÍVAR, A. Profissão professor: o itinerário profissional e a construção da escola. Bauru: EDUSC, 2002.

BRASIL. Conselho Nacional de Educação. Resolução CNE/CP № 1, 18 de Fevereiro, 2002a. Fevereiro, 2002b.

Conselho Nacional de Educação. Resolução CNE/CP № 2, 19 de

CEFD. Projeto político-pedagógico. Disponível em: http://www.ufsm.br/cefd. 2005. Acesso em: 05 ago. 2006.

DUBAR, C. A socialização: construção das identidades sociais e profissionais. Porto: Porto Ed., 1997a.

. Formação, trabalho e identidades profissionais. In: CANÁRIO, R. (Org.). Formação e situações de trabalho. Porto: Porto Ed., 1997b. p. 43-52.

FREIRE, P. Pedagogia da autonomia: saberes necessários à prática educativa. 15. ed. Rio de Janeiro: Paz e Terra, 2000.

FRIGOTTO, G. Reformas educativas e o retrocesso democrático no Brasil nos anos 90. In: LINHARES, C. (Org.). Os professores e a reinvenção da escola: Brasil e Espanha. São Paulo: Cortez, 2001, p. 57-80.

GOODSON, I.F. Dar voz ao professor: as histórias de vida dos professores e o seu desenvolvimento profissional. In: NÓVOA, A. (Org.). Vidas de professores. 2. ed. Porto: Porto Ed., 1992. p. 63-75.

JOSSO, M.C. Experiências de vida e formação. Lisboa: Educa, 2002.

JOVCHELOVITCH, S.; BAUER, M.W. Entrevista narrativa. In:BAUER, M.W.; GASKELL, G. (Eds.). Pesquisa qualitativa com texto, imagem e som: um manual prático. 2. ed. Petrópolis: Vozes, 2003, p. 90-113.

KRÜGER, L.G.; KRUG, H.N. Desvelando a formação profissional através da percepção da trajetória acadêmica. Revista Mackenzie de Educação Física e Esporte, Brasília, v. 5, n. 1, p. 77-92, jan./jul. 2006. Disponível em: <http://www.mackenzie.com.br/ editoramackenzie/revistas/edfisica/>. Acesso em: 05 ago. 2006.

$M$ ovimento, Porto Alegre, v. 15, n. 01, p. 51-70, janeiro/março de 2009. 
MARCELO GARCÍA, C. Formação de professores: para uma mudança educativa. Porto: Porto Ed., 1999.

MAZO, J.Z. A história do Centro de Educação Física da Universidade Federal de Santa Maria: um relato cronológico. 1991. 176 fls. Monografia (Especialização em Educação Física) - Universidade Federal de Santa Maria, Santa Maria, 1991.

MICHELOTTI, D. de V.; SOUZA, M. da. S. Análise do conhecimento teóricometodológico dos professores em Educação Física do CEFD/UFSM em relação à sua prática pedagógica. 2006. 15 fls. (Especialização em Educação Física Escolar) - Universidade Federal de Santa Maria, Santa Maria, 2006.

MOLINA, R.M.K. O enfoque teórico metodológico qualitativo e o estudo de caso: uma reflexão introdutória. In: TRIVIÑOS, A.N.S.; MOLINA NETO, V.M. (Orgs.). A pesquisa qualitativa na Educação Física: alternativas metodológicas. Porto Alegre: Ed. Universidade UFRGS, Sulina, 1999, p. 95-105.

MORIN, E. Os sete saberes necessários à educação do futuro. 8. ed.. São Paulo: Cortez; Brasília: UNESCO, 2003.

MUNARO, C.M. Estudo descritivo de perfil profissional do professor de Educação Física para o ensino de 1ํ e 2o graus. 1984. 180 fls. Dissertação (Mestrado em Ciência do Movimento Humano) - Universidade Federal de Santa Maria, Santa Maria, 1984.

NÓVOA, A. Formação de professores e profissão docente. In: NÓVOA, A. (Coord.). Os professores e a sua formação. Lisboa: Publicações Dom Quixote, 1992a. p. 15-33.

Os professores e as histórias de sua vida. In: NÓVOA, A. (Org.). Vidas de professores. 2. ed., Porto: Porto Ed., 1992b, p.11-30.

A formação contínua entre a pessoa-professor e a organizaçãoescola. Inovação. Lisboa, v. 4, n. 1, p. 63-76, 1991.

OLIVEIRA, V.F. de. (Org.). Narrativas e saberes docentes. ljuí: Unijuí, 2006.

PIMENTA, S.G.; ANASTASIOU, L. das G.C. Docência no ensino superior. São Paulo: Cortez, 2002.

PIMENTA, S.G.; ANASTASIOU, L. das G.C.; CAVALLET, V.J. Docência no ensino superior: construindo caminhos. In: SEVERINO, A.J.; FAZENDA, I.C.A. (Orgs.). Formação docente: rupturas e possibilidades. Campinas: Papirus, 2002, p. 207-222.

SANTOS Jr., S.L. dos. Extensão universitária: contribuições à formação inicial de professores de Educação Física. 2006. 75 fls. Monografia (Especialização em Pesquisa e Ensino do Movimento Humano) - Universidade Federal de Santa Maria, Santa Maria, 2006.

TRIVIÑOS, A.N.S. Introdução à pesquisa em ciências sociais: a pesquisa qualitativa em educação. São Paulo: Atlas, 1987.

Movimento, Porto Alegre, v. 15, n. 01, p. 51-70, janeiro/março de 2009. 
VEIGA, I.P. de A. O cotidiano da aula universitária e as dimensões do projeto político-pedagógico. In: CASTANHO, S.; CASTANHO, M.E. (Orgs.). Temas e textos em metodologia do ensino superior. 4. ed. Campinas: Papirus, 2006. p.143-152.

ZABALZA, M.A. O ensino universitário: seu cenário e seus protagonistas. Porto Alegre: Artmed, 2004.

WITTIZORECKI, Elisandro Shultz et al. Pesquisar exige interrogar-se: a narrativa como estratégia de pesquisa e de formação do(a) pesquisador(a). Movimento, Porto Alegre, v. 12, n. 2, p. 9-33, maio/ago., 2006.

Movimento, Porto Alegre, v. 15, n. 01, p. 55-74, janeiro/março de 2009. 